\title{
FT-IR Spectroscopy for the Detection of Diethylene Glycol (DEG) Contaminant in Glycerin-Based Pharmaceutical Products and Food Supplements
}

\author{
Ayman Y. Hammoudeh, Safwan M. Obeidat, ${ }^{\star}$ Eman Kh. Abboushi and \\ Amal M. Mahmoud
}

Chemistry Department, Faculty of Science, Yarmouk University, Irbid, Jordan.

*Correspondingauthor: E-mail:Safwan@yu.edu.jo; Safobeidat@yahoo.com

Tel: 962-27211111

Received: 10-10-2019

\begin{abstract}
Identification and determination of diethylene glycol (DEG) in glycerin-based products was successfully achieved using FT-IR spectroscopy. Studied samples included $0.5 \%$ to $20 \%$ by mass DEG spiked into cough syrup, two paracetamol syrup formulations, and two food supplements. The characteristic DEG wavenumbers at $881 \mathrm{~cm}^{-1}$ and $1083 \mathrm{~cm}^{-1}$ were used for its quantitative determination in the studied samples. A very good accuracy in determining the DEG fraction was achieved with a mean error $\%$ of $\pm 2.02 \%$ to $\pm 7.69 \%$ upon using the corrected absorbance at $881 \mathrm{~cm}^{-1}$. The corrected absorbance at $1083 \mathrm{~cm}^{-1}$ band was used in the case of paracetamol formulations and resulted in a mean error\% ranging from $\pm 2.50 \%$ to $\pm 10.28 \%$. The values of limit of detection of the current method ranged from $0.051 \%$ to $0.068 \%$ DEG for all studied samples.
\end{abstract}

Keywords: FT-IR; diethylene glycol (DEG); glycerin; pharmaceutical products; food supplements.

\section{Introduction}

Glycerin (or glycerol) is a popular alcohol with a wide range of applications in pharmaceutical, food, and personal care products industries. Glycerin acts as a humectant, preservative, and lubricant; it can be found in more than 2,000 products, including toothpaste, mouthwash, and pain relief medications. ${ }^{1,2}$ Usually, it is prepared from fats and oils and may also be obtained as a by-product from some biofuel production reactions. ${ }^{3}$ The global demand for glycerin is continuously increasing. This encouraged greedy sellers to adulterate glycerin with diethylene glycol (DEG) that is less expensive and has similar physical properties. However, DEG is toxic to humans. Adulterating glycerin with DEG has caused many fatalities in a number of countries around the world. ${ }^{4}$ For example, it was reported that many death cases among children in Nigeria in 2008 were due to DEG poisoning. ${ }^{5}$ In 2006, cough syrups in Panama were manufactured with DEG instead of glycerine, resulting in 51 death cases. ${ }^{2}$ In 1996, in Haiti, at least 59 children died of acute kidney failure caused by contaminated paracetamol syrup containing up to $26 \%$ DEG. ${ }^{6,7}$ More poisoning cases around the world were reported in much detail in reference ${ }^{2}$. Recommended Food and Drug Administration (FDA) limits of potential DEG contamination are $0.1 \%$ to $12.7 \%$ in pharmaceutical formulations of liquid excipients and $0.1 \%$ in sorbitol and other excipient solutions. ${ }^{8}$ Therefore, many analytical methods of identifying and determining DEG in contaminated glycerin were reported. Gas chromatography (GC) was used for DEG quantitation in some food products, human sera, and pharmaceutical products. ${ }^{9-11} \mathrm{GC}$ combined with mass spectrometry (GC-MS) was also reported for confirming the identity of different glycols and DEG in bait fish, human plasma, and electronic cigarettes. ${ }^{12-14}$ Thin layer chromatography (TLC) was also employed to detect the presence of DEG in toothpastes. ${ }^{15}$ A combination of GC, IR spectroscopy, and TLC was used to test the purity of glycerin. ${ }^{6}$ Fourier transform infrared (FT-IR) and near-infrared (NIR) spectroscopic techniques were reported as viable, simple, cost effective, and rapid methods for the identification and quantification of DEG in glycerin-based cough syrups. ${ }^{5}$ In a recent study, mid-IR spectroscopy has been shown to be a simple and rapid technique to determine possible DEG contamination in glycerin raw materials. ${ }^{16}$ The current work addresses the 
applicability of mid-IR spectroscopy for determining possible DEG contamination in more complex glycerin-containing commercial products whose other constituents may also interfere and absorb in the spectroscopic range of interest; these include a cough syrup, two paracetamol syrup formulations, and two food supplements.

\section{Experimental}

\section{1. Materials and Methods}

The cough syrup Hederal (product of Delass, Jordan) was purchased from a local pharmacy in the City of Irbid in Jordan. It consists of the dried leaf of Hedera helix (an ivy leaf) as expectorant, in addition to glycerin, sorbitol, propylene glycol, polysorbate (tween 80 ), sucrose syrup, strawberry flavor, and water. Two glycerin-based food supplements were also studied; a natural plant based glycerite sweetener that consists of stevia plant extract, glycerin, and water (brand name: Better Stevia, NOW Foods, USA), and a liquid herbal extract claimed to support healthy nervous system and consists of glycerin, water, and a lemon balm extract (brand name: Lemon Balm, Herb Pharm, USA). Both supplements were purchased from local markets in USA. Two paracetamol syrup formulations were prepared according to the procedure described in reference ${ }^{17}$. All studied samples were spiked with known amounts of DEG ranging from about $0.5 \%$ to $20 \%$ by mass. Glycerin (99.5\%) and DEG (99\%) were purchased from Tedia (USA) and Vickerings (UK), respectively.

\section{2. Instrumentation and Data Acquisition}

All infra-red measurements were performed in attenuated total reflection (ATR) mode using a Bruker Alpha FT-IR spectrometer equipped with a deuterated triglycine sulfate (DTGS) detector and a zinc selenide window. All IR spectra in this study were collected in triplicate (i.e. three IR spectra were taken and averaged for each solution) in the range $700-4000 \mathrm{~cm}^{-1}$ with a resolution of $4 \mathrm{~cm}^{-1}$ against air as a background. For each test product investigated in this work, calibration curves were constructed by plotting the absorbance (peak intensity without baseline correction) at selected wavenumbers versus the percentage of DEG spiked in the tested samples. Spiking the test solutions with DEG leads however to decreased percentages of the original constituents in the test solutions. A correction for this behavior was undertaken, subtracting thereby the expected absorbance contribution of the original constituents of the test product from the actually measured absorbance. This contribution has been estimated to be the mass percent of test product in the final solution (i.e. after spiking with DEG) multiplied by the absorbance of the original test product at the wavenumbers of interest in this study $\left(881\right.$ and $\left.1083 \mathrm{~cm}^{-1}\right)$. The correction is shown in equations (1)-(3) for the absorbance at
$881 \mathrm{~cm}^{-1} ; A$ stands for the actually measured absorbance, product $\%$ is the percentage of tested product in the final solution after spiking with $\mathrm{DEG}, A_{\mathrm{DEG}}$ is the magnitude of absorbance associated with DEG:

$$
\begin{aligned}
& A\left(881 \mathrm{~cm}^{-1}\right)= A_{D E G}\left(881 \mathrm{~cm}^{-1}\right)+ \\
&+A_{\text {product }}\left(881 \mathrm{~cm}^{-1}\right) \\
& A\left(881 \mathrm{~cm}^{-1}\right)= A_{D E G}\left(881 \mathrm{~cm}^{-1}\right)+\frac{\text { product } \%}{100} \times \\
& \times A_{\text {unspiked product }}\left(881 \mathrm{~cm}^{-1}\right) \\
& A_{D E G}=A\left(881 \mathrm{~cm}^{-1}\right)-\frac{\text { product } \%}{100} \times \\
& \times A_{\text {unspiked product }}\left(881 \mathrm{~cm}^{-1}\right)
\end{aligned}
$$

\section{Results and Discussion}

The IR spectrum of DEG is rich in bands, but only those below $1200 \mathrm{~cm}^{-1}$ are useful in the quantification of DEG in glycerin-containing systems. ${ }^{16}$ Figure 1 represents the IR spectra of neat DEG and neat glycerin in the spectral range $810-1170 \mathrm{~cm}^{-1}$. The band around $1030 \mathrm{~cm}^{-1}$ is assigned to the $\mathrm{C}-\mathrm{O}$ stretching vibration of primary alcohol, ${ }^{18}$ and is found both in glycerin and DEG. In glycerin, the band at $1110 \mathrm{~cm}^{-1}$ is attributed to the $\mathrm{C}-\mathrm{O}$ stretching vibration of the secondary alcohol group. This band is absent in DEG due to the lack of secondary $\mathrm{OH}$ groups. Instead, a DEG characteristic band is observed at $1085 \mathrm{~cm}^{-1}$ which is attributed to the asymmetric $\mathrm{C}-\mathrm{O}-\mathrm{C}$ stretch mode, whereas the DEG bands at $881 \mathrm{~cm}^{-1}$ and $860 \mathrm{~cm}^{-1}$ are attributed to the $\mathrm{CH}_{2}$ rocking mode. ${ }^{16}$ In a previous study, ${ }^{16}$ the DEG characteristic bands at $1085 \mathrm{~cm}^{-1}$ and $881 \mathrm{~cm}^{-1}$ were used successfully to quantify DEG in a glycerin raw material. Hence, these bands may hold the poten-

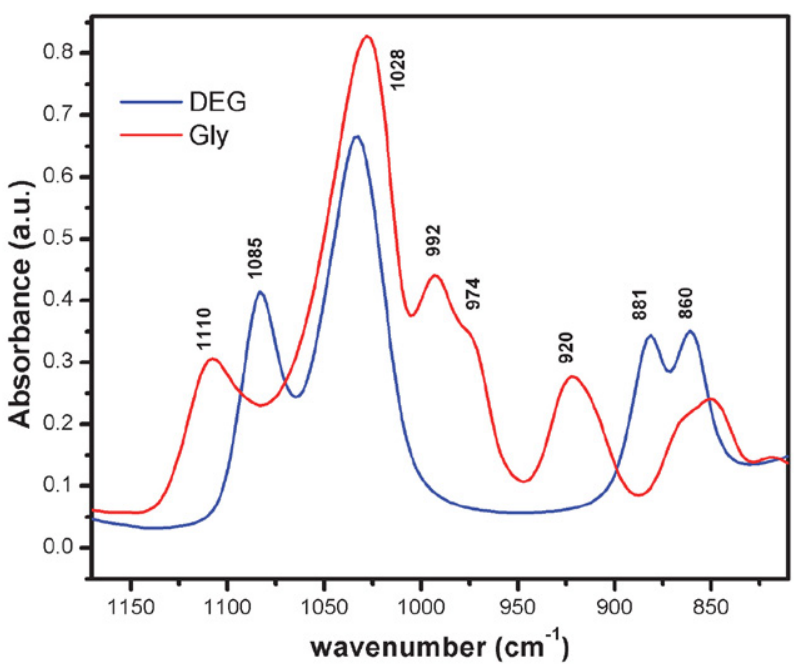

Figure 1: IR spectra of neat glycerin (red) and DEG (blue) in the spectral range $810-1170 \mathrm{~cm}^{-1}$. The characteristic bands are labeled by the wavenumbers at band maxima. 
tial for determining DEG in real glycerin-based products. These bands were tested in the current study to quantify spiked DEG in pharmaceutical products and food supplements which contain not only glycerin and water, but also other constituents that may also absorb in the IR range of interest and make the analysis more difficult.

\section{1. Cough Syrup Hederal}

Seventeen syrup samples were spiked with different amounts of DEG resulting in different DEG weight percentages in the samples, ranging from approximately $1 \%$ to $16 \%$. Figure 2 shows how the intensity of the IR bands at $1083,1036,881$, and $860 \mathrm{~cm}^{-1}$ increases with increased DEG\%. All these bands belong to DEG but may also have contributions from other constituents. Sorbitol, for example, shows an IR band at $1078 \mathrm{~cm}^{-1}$, glycerin at $1036 \mathrm{~cm}^{-1}$, sucrose has a wide absorption profile from $960 \mathrm{~cm}^{-1}$ to $1095 \mathrm{~cm}^{-1}$. The absorption at $881 \mathrm{~cm}^{-1}$ is mostly due to DEG with minimum contribution from the other constituents. Figure 2 shows also that for certain bands, e.g. the glycerin characteristic bands at $1110 \mathrm{~cm}^{-1}$ and $994 \mathrm{~cm}^{-1}$, the intensity drops in general with increased amounts of spiked DEG, apparently due to sample dilution with DEG.

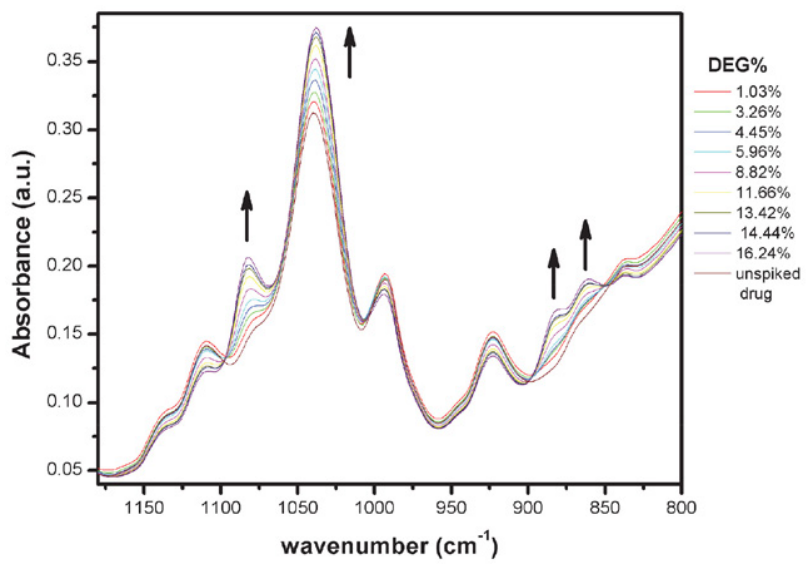

Figure 2: FT-IR spectra of Hederal unspiked and spiked with different DEG\%.

The two DEG characteristic bands at $881 \mathrm{~cm}^{-1}$ and $1083 \mathrm{~cm}^{-1}$ were further investigated for the quantitative determination of spiked DEG in Hederal. The intensity of the DEG spiked samples at $881 \mathrm{~cm}^{-1}$ and $1083 \mathrm{~cm}^{-1}$ was plotted in the calibration curves shown in Figure 3. For both wavenumbers, a straight line was obtained with $R^{2}$ values of 0.9963 and 0.9984 , respectively. In order to find the absorbance contribution due to DEG only, the absorbance measured at $881 \mathrm{~cm}^{-1}$ or $1083 \mathrm{~cm}^{-1}$ was corrected according to equation (3) as explained in the experimental part. The corrected absorbance (i.e. of DEG) at $881 \mathrm{~cm}^{-1}$ and $1083 \mathrm{~cm}^{-1}$ is plotted in Figure 4 versus DEG\%. The correlation coefficients of the obtained linear relations were improved, reading 0.9985 for DEG absorbance at $881 \mathrm{~cm}^{-1}$ and 0.9992 for that at $1083 \mathrm{~cm}^{-1}$.

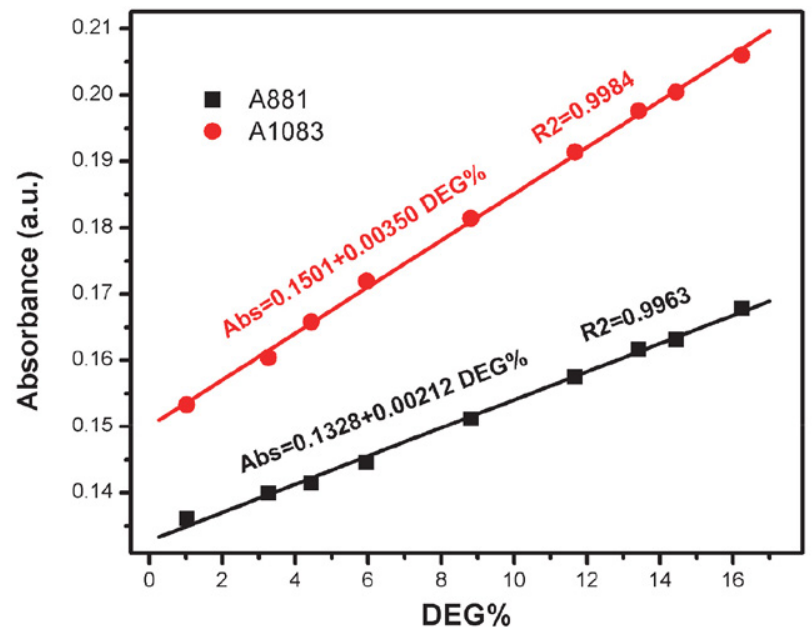

Figure 3. The intensity of the IR bands at $881 \mathrm{~cm}^{-1}$ and $1083 \mathrm{~cm}^{-1}$ versus DEG\% in spiked Hederal samples.

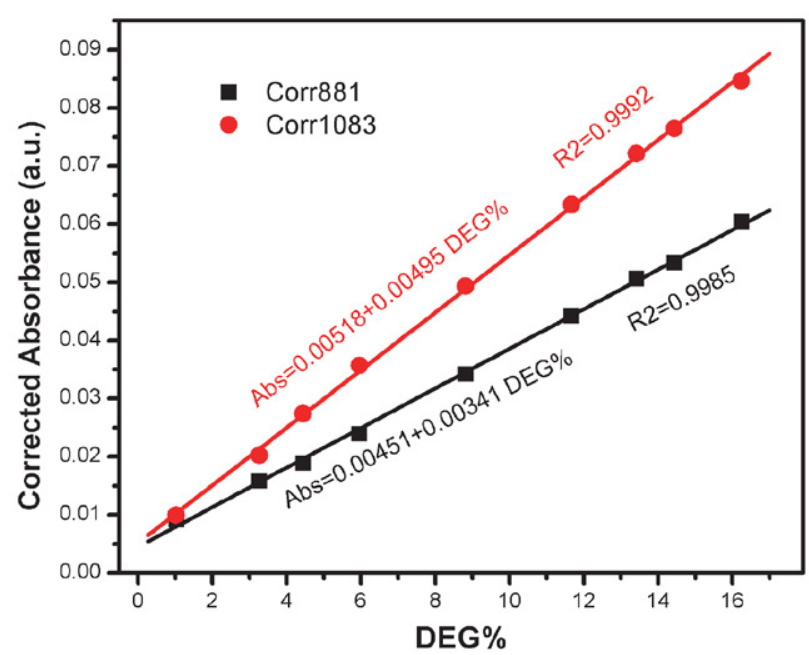

Figure 4. Corrected DEG absorbance at $881 \mathrm{~cm}^{-1}$ and $1083 \mathrm{~cm}^{-1}$ versus its percentage in spiked Hederal samples.

The equations describing the linearity of the calibration model were then used to determine the concentration of DEG in a validation set of seven samples of spiked Hederal. A very good agreement between the actual and the predicted DEG concentrations in the validation samples was obtained as displayed in Table 1. From this table, it is quite clear that the calibration curve of corrected absorbance gives more accurate values than that without correction (an average error\% of $\pm 2.0 \%$ for the absorbance at $881 \mathrm{~cm}^{-1}$ compared to $\pm 3.3 \%$ when no correction was undertaken). In addition, the absorbance at $881 \mathrm{~cm}^{-1}$ is a better measure of DEG\% than that at $1083 \mathrm{~cm}^{-1}$ (average er- 
ror $\%$ of $\pm 2.02 \%$ for corrected absorbance at $881 \mathrm{~cm}^{-1}$ compared to $\pm 4.38 \%$ at $1083 \mathrm{~cm}^{-1}$ ) as listed in Table 1 . The limit of detection (LOD) for this drug was calculated based on the $881 \mathrm{~cm}^{-1}$ band and found to be $0.051 \mathrm{DEG} \%$.

Table 1: Actual and predicted DEG\% in Hederal and associated errors from IR absorbance at $881 \mathrm{~cm}^{-1}$ and $1083 \mathrm{~cm}^{-1}$.

\begin{tabular}{ccccc}
\hline $\mathbf{8 8 1} \mathbf{~ c m}^{-\mathbf{1}}$ & \multicolumn{2}{c}{ Predicted DEG\% } & \multicolumn{2}{c}{ Error\% } \\
\hline $\begin{array}{c}\text { DEG\% } \\
\text { actual }\end{array}$ & $\begin{array}{c}\text { without } \\
\text { correction }\end{array}$ & $\begin{array}{c}\text { after } \\
\text { correction }\end{array}$ & $\begin{array}{c}\text { without } \\
\text { correction }\end{array}$ & $\begin{array}{c}\text { after } \\
\text { correction }\end{array}$ \\
\hline 1.90 & 2.06 & 1.99 & 8.11 & 4.68 \\
3.72 & 3.66 & 3.67 & 1.75 & 1.37 \\
5.38 & 4.99 & 5.13 & 7.30 & 4.80 \\
7.62 & 7.68 & 7.63 & 0.83 & 0.27 \\
10.02 & 9.76 & 9.84 & 2.63 & 1.87 \\
12.63 & 12.67 & 12.63 & 0.37 & 0.01 \\
14.27 & 14.58 & 14.43 & 2.18 & 1.13 \\
& & Mean & $\mathbf{3 . 3 1}$ & $\mathbf{2 . 0 2}$ \\
\hline
\end{tabular}

\begin{tabular}{ccccc}
\hline $\mathbf{1 0 8 3} \mathbf{~ c m}^{-\mathbf{1}}$ & \multicolumn{2}{c}{ Predicted DEG\% } & \multicolumn{2}{c}{ Error\% } \\
\hline $\begin{array}{c}\text { DEG\% } \\
\text { actual }\end{array}$ & $\begin{array}{c}\text { without } \\
\text { correction }\end{array}$ & $\begin{array}{c}\text { after } \\
\text { correction }\end{array}$ & $\begin{array}{c}\text { without } \\
\text { correction }\end{array}$ & $\begin{array}{c}\text { after } \\
\text { correction }\end{array}$ \\
1.90 & 1.63 & 1.71 & 14.54 & 9.88 \\
3.72 & 3.93 & 3.88 & 5.66 & 4.20 \\
5.38 & 5.17 & 5.24 & 3.94 & 2.66 \\
7.62 & 8.71 & 8.40 & 14.39 & 10.25 \\
10.02 & 10.29 & 10.22 & 2.65 & 1.93 \\
12.63 & 12.77 & 12.73 & 1.13 & 0.84 \\
14.27 & 14.31 & 14.30 & 0.26 & 0.22 \\
& & Mean & $\mathbf{6 . 0 8}$ & $\mathbf{4 . 2 8}$ \\
\hline
\end{tabular}

\section{2. Formulations of Paracetamol Syrup}

In a study of pharmaceutical solution formulations for paracetamol, ${ }^{17}$ six paracetamol syrup formulations were tested for the stability of active ingredient. Two of these formulations (A and B) were investigated in this work for the identification of possible contamination with DEG by means of FT-IR. The approximate solvent composition of these formulations is given in Table 2 .

Table 2: Approximate solvent composition of two formulations for paracetamol syrup.

\begin{tabular}{lcccc}
\hline & Glycerin/\% & Sorbitol/\% & Ethanol/\% & Water/\% \\
\hline Formulation A & 33.1 & 30.2 & 6.7 & 30.0 \\
Formulation B & 36.7 & 9.6 & 26.9 & 26.8 \\
\hline
\end{tabular}

Both formulations have comparable amounts of glycerin. Formulation B is four times richer in ethanol (26.9\%) with only $9.6 \%$ of sorbitol, while formulation A contains small amounts of ethanol (6.7\%) with sorbitol being a major constituent (30.2\%). DEG was spiked in these formulations with a mass percent ranging from $0.8 \%$ to $16 \%$. The collected IR spectra as well as the correlation between DEG\% and corrected absorbance at $1083 \mathrm{~cm}^{-1}$ and $881 \mathrm{~cm}^{-1}$ are presented in Figure 5. Obviously, the presence of ethanol and sorbitol complicates the absorbance behavior at $881 \mathrm{~cm}^{-1}$. The effect of ethanol seems greater as it can be recognized in Figure 5 that a large absorption band appears around $880 \mathrm{~cm}^{-1}$ in the unspiked formulation $\mathrm{B}$, due to the presence of large amounts of ethanol. The absorbance at $1083 \mathrm{~cm}^{-1}$ is also affected by the presence of sorbitol and ethanol; it is higher in unspiked formulation $\mathrm{A}$ than in unspiked formulation $\mathrm{B}$, but the band shape experiences in general no significant change. The above example of paracetamol syrup formulations shows that the absorbance behavior in the IR region of interest for DEG determination is very sensitive to the formulation composition, but good estimates for DEG can still be made after correcting the absorbance for the contribution of unspiked reference formulation (Figure 5). In formulation B, however, DEG\% below $1 \%$ are not well reflected by the linear correlation given in Figure 5, suggesting that the uncertainty in the determination of such low amounts of DEG $(<1 \%)$ becomes large if the original formulation shows strong IR absorption especially at $881 \mathrm{~cm}^{-1}$.

Similar findings were also noticed upon studying a validation set that contains five DEG-spiked paracetamol samples from each formulation of DEG ranging from about $2.5 \%$ to $13.0 \%$. The results of DEG analysis at $1083 \mathrm{~cm}^{-1}$ are displayed in Table 3. Once more, the error\% calculations showed that a better accuracy is obtained in case of formulation A, with mean error\% value of $\pm 2.86 \%$, versus $\pm 10.28 \%$ for formulation B. More specifically, Table 3 shows a much larger error\% for DEG percentages smaller than $5 \%$ in formulation $\mathrm{B}$ than in formulation $\mathrm{A}$. We find for example for the DEG\% of $2.5 \%$ and $~ 5 \%$ an error $\%$ of $\pm 34.5 \%$ and $\pm 9.66 \%$ in the case of formulation B compared to only $\pm 3.11 \%$ and $\pm 1.66 \%$, respectively, in the case of formulation A. This large uncertainty in the DEG\% below $5 \%$ in formulation $\mathrm{B}$ is obviously associated with the presence of high amounts of ethanol (26.9\%) and not sorbitol which is present in formulation $\mathrm{A}$ in almost the same percentage $(30.2 \%)$ as ethanol in formulation B. Apparently, the presence of high percentages of ethanol in test product presents a limitation for the spectral analytical technique suggested in this work, especially at DEG\% $<5 \%$. The DEG\% LOD values for both formulations were calculated based on the $1083 \mathrm{~cm}^{-1}$ band and found to be $0.058 \%$ and $0.067 \%$ for formulation $\mathrm{A}$ and $\mathrm{B}$, respectively.

\section{3. Food Supplements (Better Stevia and Lemon Balm)}

Better Stevia and Lemon Balm samples were spiked with DEG in the range $2-20 \%$. The absorbance at 

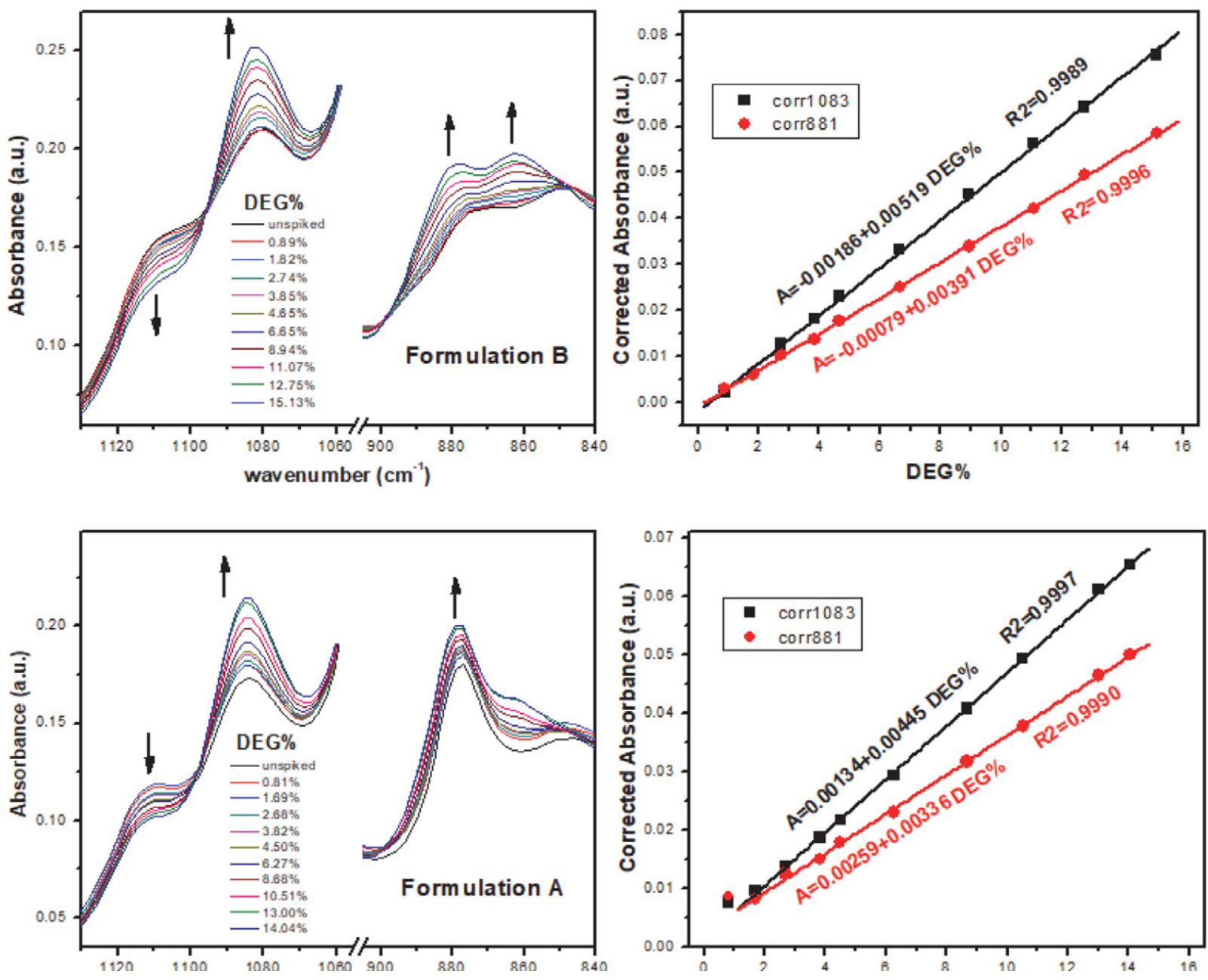

Figure 5: FT-IR spectra of paracetamol formulations (A and B) unspiked and spiked with different DEG\% (left). Corrected DEG absorbance at $881 \mathrm{~cm}^{-1}$ and $1083 \mathrm{~cm}^{-1}$ versus its percentage in spiked samples of each formulation (right).

Table 3: Actual and predicted DEG percentages from corrected absorbance at $1083 \mathrm{~cm}^{-1}$ of two formulations for paracetamol syrup

\begin{tabular}{lccccc}
\hline & \multicolumn{2}{c}{ Formulation A } & \multicolumn{3}{c}{ Formulation B } \\
\hline $\begin{array}{l}\text { DEG\% } \\
\text { actual }\end{array}$ & $\begin{array}{c}\text { Calculated } \\
\text { DEG\% }\end{array}$ & Error\% & $\begin{array}{c}\text { DEG\% } \\
\text { actual }\end{array}$ & $\begin{array}{c}\text { Calculated } \\
\text { DEG\% }\end{array}$ & Error\% \\
\hline 2.52 & 2.44 & 3.11 & 2.50 & 3.36 & 34.50 \\
4.94 & 4.85 & 1.68 & 4.58 & 5.020 & 9.66 \\
6.95 & 6.58 & 5.26 & 6.10 & 7.32 & 4.66 \\
11.07 & 10.66 & 3.65 & 11.052 & 10.86 & 1.77 \\
13.14 & 13.05 & 0.63 & 12.77 & 12.88 & 0.80 \\
& Mean & $\mathbf{2 . 8 6}$ & & & $\mathbf{1 0 . 2 8}$ \\
\hline
\end{tabular}

$881 \mathrm{~cm}^{-1}$ as well as that at $1083 \mathrm{~cm}^{-1}$ were used to quantify DEG in the spiked samples. Like DEG quantification in Hederal cough syrup, the absorbance at $881 \mathrm{~cm}^{-1}$ gave better results, as shown below, the reason why in the following text, and for the sake of clarity, only the results based on the absorbance at $881 \mathrm{~cm}^{-1}$ are presented. Figure 6 shows the corrected absorbance calibration curves for the absorbance only at $881 \mathrm{~cm}^{-1}$. Straight lines of $R^{2}$ values of 0.9985 and 0.9989 were obtained for Better Stevia and Lemon Balm, respectively. The obtained calibration equations shown in Figure 6 were then used to determine the DEG\% in two validation sets consisting of 11 samples each. Tables 4 and 5 show the real and predicted DEG\% for all samples of the validation sets. Obviously, the current method represents a reliable method for determining the DEG\% in the studied food supplements based on the very good agreement of the DEG\% in actual and predicted concentrations. The good accuracy of the current work is evidenced by the low mean error\% values, which were $\pm 3.34 \%$ and $\pm 7.69 \%$ for Better Stevia and Lemon Balm, respectively. These values are smaller than those obtained when the absorbance at $1083 \mathrm{~cm}^{-1}$ is used to quantify spiked DEG where mean error $\%$ of $\pm 7.77 \%$ and $\pm 9.46 \%$ were obtained for Better Stevia and Lemon Balm, respectively. LOD values based on the absorbance at $881 \mathrm{~cm}^{-1}$ were computed for both products and were found to be $0.055 \%$ for Better Stevia and $0.068 \%$ for Lemon Balm. 

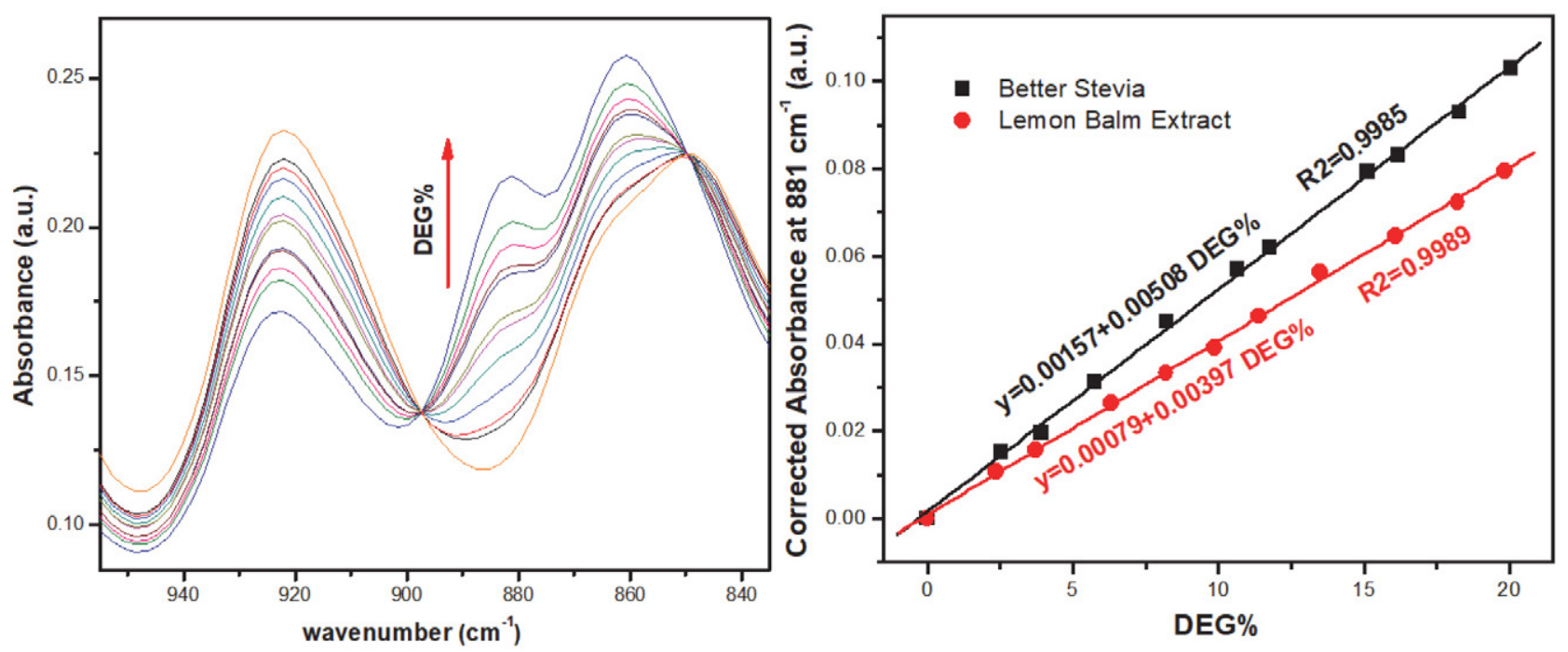

Figure 6: FT-IR spectra of Better Stevia spiked with DEG (left) and corrected absorbance at $881 \mathrm{~cm}^{-1}$ for DEG-spiked Better Stevia and Lemon Balm Extract (right).

Table 4: Actual and predicted DEG percentages from corrected absorbance at $881 \mathrm{~cm}^{-1}$ for Better Stevia.

\begin{tabular}{ccc}
\hline Actual DEG\% & Calculated DEG\% & Error\% \\
\hline 2.61 & 2.93 & 12.14 \\
4.12 & 4.25 & 3.16 \\
6.43 & 6.47 & 0.52 \\
8.64 & 8.23 & 4.82 \\
9.75 & 9.91 & 1.67 \\
11.94 & 11.85 & 0.78 \\
14.01 & 14.06 & 0.29 \\
15.66 & 15.33 & 2.11 \\
20.30 & 19.38 & 4.56 \\
Mean & 3.34 & \\
\hline
\end{tabular}

Table 5: Actual and predicted DEG percentages from corrected absorbance at $881 \mathrm{~cm}^{-1}$ for Lemon Balm Extract

\begin{tabular}{ccc}
\hline Actual DEG\% & Calculated DEG\% & Error\% \\
\hline 2.30 & 2.74 & 18.90 \\
3.63 & 3.17 & 12.71 \\
6.08 & 6.56 & 7.76 \\
8.07 & 8.48 & 5.03 \\
9.92 & 10.44 & 5.28 \\
13.29 & 14.02 & 5.49 \\
13.79 & 14.67 & 6.40 \\
16.16 & 17.17 & 6.25 \\
18.36 & 19.53 & 6.36 \\
19.66 & 20.19 & 2.76 \\
- & mean & 7.69 \\
\hline
\end{tabular}

\section{Conclusions}

In the current work, IR spectroscopy is shown to be a relatively simple, fast and accurate method for determin- ing DEG in spiked glycerin-based cough syrup, drug formulations, and food supplements. From test sets of spiked samples, two main characteristic DEG bands (881 and $1083 \mathrm{~cm}^{-1}$ ) were found to be, for this purpose, the best. Hence, a linear regression analysis based on these test sets was employed for DEG determination in validation sets of samples of each studied product. The results showed a very good agreement of the real and predicted DEG values in all samples. Accuracy has also been improved upon using corrected absorbance values where the absorbance before adding DEG was subtracted from the total absorbance after spiking with DEG. This result was evidenced by the decreased mean error\% values. For the studied cough syrup and food supplements, the mean error\% is smaller when the absorbance at $881 \mathrm{~cm}^{-1}$ is considered for DEG quantification in comparison to quantification based on the absorbance at $1083 \mathrm{~cm}^{-1}$, reflecting the better accuracy associated with the band at $881 \mathrm{~cm}^{-1}$ for DEG determination in these products. However, in the case of paracetamol formulations, the band at $1083 \mathrm{~cm}^{-1}$ was found to be better than the band at $881 \mathrm{~cm}^{-1}$ for DEG determination due to the presence of high ethanol concentrations in these samples that disturb and complicate the absorbance behavior around $880 \mathrm{~cm}^{-1}$.

\section{Conflict of Interest}

The authors declare no conflict of interest.

\section{References}

1. S. Alfred, P. Coleman, D. Harris, T. Wigmore, E. Stachowski, A. Graudins, Clin. Toxicol., 2005, 43(3), 155-159.

DOI:10.1081/CLT-200057875

2. B. D. Barr, et al., J. Anal. Toxicol., 2007, 31(6), 295-303. 
3. A. B. Leoneti, V. Aragão-Leoneti, Sonia, V. W. B. Oliveira, Renew. Energy, 2012, 45, 138-145.

DOI:10.1016/j.renene.2012.02.032

4. L. A. Ferrari, L. Giannuzzi, Forensic Sci Int., 2005, 153, 45-51. DOI:10.1016/j.forsciint.2005.04.038

5. M. K. Ahmed, M. P. McLeod, J. Nézivar, A. W. Giuliani, Spectroscopy, 2010, 24, 601-608. DOI:10.1155/2010/608749

6. M. T. S. R. Gomes, M. I. S. Veriâ ssimo, J. A. B. P. Oliveira, J. Pharm. Pharmacol., 1999, 51, 233-236.

7. L. Blecher, A. Mercill, Pharm. Technol., 1998, 22, 50-54.

8. G. Holloway, R. Maheswaran, A. Leeks, S. Bradby, S. Wahab, J. Pharm. Biomed. Anal., 2009, 51, 507-511.

DOI:10.1016/j.jpba.2009.08.025

9.L. Castle, H. R. Cloke, J. R. Startin, J. Gilbert, J AOAC Int., 1988, 71, 499-502.

10. J. B. Brooks, M. T. Basta, C. C. Alley, J. S. Holley, A. M. El Kholy, J. Chromatogr. 1984, 309, 269-272.

DOI:10.1016/0378-4347(84)80034-1
11. P. Baffi, S. Elneser, M. Baffi, M. Demelin, J. AOAC Int. 2000, 83, 793-801.

12. J. E. Matusik, P. P. Eilers, E. M. Waldron, S. M. Conrad, J. A. Sphon, J. AOAC Int., 1993, 76, 1344-1347.

13. J. E. Maurer, C. Kessler, Arch. Toxicol., 1988, 62, 66-69. DOI:10.1007/BF00316260

14. V. Varlet, K. Farsalinos, M. Augsburger, A. Thomas, J. Etter, Int. J. Environ. Res. Public. Health, 2015, 12(5), 4796-4815. DOI:10.3390/ijerph120504796

15. A. S. Kenyon, S. Xiaoye, W. Yan, N.G. Wai Har, R. Prestidge, K. Sharp, J. AOAC Int.1988, 81, 44-49.

16. S. M. Obeidat, A. Y. Hammoudeh, A. Mahmoud, Spectroscopy Lett., 2019, 52 (1), 60-65.

DOI:10.1080/00387010.2018.1556220

17. A. Bedri, S. Vehbi, L. Azem, I. Hilmi, Med. Arh., 2012, 66 ( 1), 5-8.

18. P. Harder, M. Grunze, R, Dahint, G. M. Whitesides, P. E. Laibinis, J. Phys. Chem. B, 1998, 102, 426-436.

DOI:10.1021/jp972635z

\section{Povzetek}

S pomočjo FT-IR spektroskopije smo uspešno identificirali in določili dietilen glikol (DEG) v proizvodih na osnovi glicerina. Preiskovani vzorci so vsebovali od $0,5 \%$ do $20 \%(\mathrm{~m} / \mathrm{m})$ DEG, dodanega sirupu proti kašlju, dvema pripravkoma sirupa s paracetamolom in dvema prehranskima dopolniloma. Za kvantitativno določitev DEG v preiskovanih vzorcih smo uporabili karakteristični valovni števili za DEG pri $881 \mathrm{~cm}^{-1}$ in $1083 \mathrm{~cm}^{-1}$. Z uporabo korigirane absorbance pri $881 \mathrm{~cm}^{-1}$ smo dosegli zelo dobro točnost pri določitvi deleža DEG s povprečno napako $\pm 2,02 \%$ do $\pm 7,69 \%$. Korigirano absorbanco pri traku $1083 \mathrm{~cm}^{-1}$ smo uporabili za paracetamolne pripravke in dobili povprečno napako v obnočju $\pm 2,50$ $\%$ do $\pm 10,28 \%$. Vrednosti meje zaznave pri predstavljeni metodi so bile v območju 0,051 \% do 0,068 \% DEG za vse preiskovane vzorce.

Except when otherwise noted, articles in this journal are published under the terms and conditions of the Creative Commons Attribution 4.0 International License 